\title{
UJI APLIKASI EKSTRAK KASAR BUAH PINANG, AKAR TUBA, PATAH TULANG, DAN DAUN NIMBA TERHADAP KEONG EMAS (POMACEA SP.) DI RUMAH KACA
}

\author{
Lestari Wibowo ${ }^{1}$, Indriyati ${ }^{1}$, dan Solikhin ${ }^{1}$
}

\begin{abstract}
S
Application test of crude extracts of pinang fruit, tuba root, patah tulang, and neem leaf on golden apple snail (Pomacea sp.) in green house. This research was conducted to evaluate the effect of four botanical crude extracts namely Areca catechu, Derris eliptica, Euphorbia tirucalli and Azadirachta indica on golden apple snails under green house condition. All experiment units were arranged in randomized completely design consisting of some levels of concentration (titer). The result showed that low concentration of the crude extract of $A$. catechu fruit $(0,5 \mathrm{~g} / 1)$ and crude extracts of $D$. elliptica root $(1 \mathrm{~g} / \mathrm{l})$ were very toxic, indicated by all snails tested were died. Mortality of snails tested caused by crude extract of A. indica was $100 \%$ at the concentration of $4 \mathrm{~g} / \mathrm{l}$, meanwhile crude extract of E. tirucalli was only $84 \%$ at a higher concentration of crude extract ( $8 \mathrm{~g} / 1)$ occurring 96 hours after application.
\end{abstract}

Key words : golden apple snail, botanical crude extract, mortality

\section{PENDAHULUAN}

Keong emas (Pomacea sp.) dalam kurun waktu sepuluh tahun terakhir menjadi salah satu hama utama pada tanaman padi sawah di Indonesia. Pada tahun 1996, keong emas dilaporkan telah menyebar di 14 provinsi (Pitojo, 1996). Pada musim tanam padi tahun 2004-2005 keong emas menimbulkan kerusakan ribuan hektar tanaman padi yang tersebar di daerah serangan seperti Nganjuk (Jawa Timur), Kuningan, Indramayu, dan Cianjur, serta di wilayah Kalimantan Selatan dan Sulawesi Selatan (Kompas, 2005; Indomedia, 2005; Fajar, 2005; Pikiran Rakyat, 2005).

Keong emas merupakan hama tanaman padi muda yang berumur kurang dari 30 hari. Hama ini merusak tanaman padi dengan cara memakan bagian pangkal batang sehingga dapat menyebabkan kematian tanaman (Alis, 1997). Perkembangbiakkan hama ini sangat cepat, sehingga petani kesulitan dalam pengendaliannya. Pengendalian secara mekanis dengan mengambil keong emas yang ada, belum memberikan hasil yang memuaskan. Petani umumnya tidak melakukan pengendalian secara kimiawi terhadap keong emas karena kurang efektif dan berbahaya bagi lingkungan (Djajasasmita, 1999).

Upaya pengendalian secara terpadu terus dikembangkan. Selain teknik pengendalian secara mekanis yang saat ini telah diterapkan, dipandang perlu dipadukan dengan teknik pengendalian lainnya yang sesuai dengan prinsip-prinsip pengendalian hama terpadu (PHT). Salah satu teknik pengendalian yang dikembangkan dalam PHT adalah pemanfaatan bahan tumbuhan sebagai pestisida nabati (Oka, 1994).

Tumbuhan yang berpotensi untuk digunakan sebagai pestisida nabati jumlahnya tidak kurang dari 2400 jenis (Grainge \& Achmed, 1988). Tumbuhan tersebut mengandung bahan yang dapat membunuh serangga, tungau, menekan pertumbuhan bakteri, cendawan, dan ada pula yang dapat membunuh hewan moluska. Akar tuba dan patah tulang selain dapat membunuh ikan, juga dapat membunuh keong dan kerang di air (Direktorat Bina Perlindungan Tanaman Perkebunan,1994). Buah pinang menurut petani padi di Sumatera Barat dalam salah satu tayangan televisi swasta tahun 1998, mengatakan buah pinang dapat digunakan untuk membunuh keong emas di sawah. Tanaman nimba telah digunakan sebagai insektisida nabati, mungkin dapat pula diteliti potensinya sebagai moluskisida nabati. Penelitian pendahuluan menunjukkan bahwa ekstrak kasar buah pinang, akar tuba, patah tulang, dan daun nimba dapat menyebabkan mortalitas keong emas. Namun seberapa besar mortalitas keong emas yang dapat ditimbulkan oleh masing-masing tumbuhan tersebut masih perlu diteliti lebih lanjut.

Penelitian ini bertujuan untuk meneliti pengaruh aplikasi ekstrak kasar buah pinang (Areca catechu), akar tuba (Derris elliptica), patah tulang (Euphorbia

\footnotetext{
${ }^{1}$ Jurusan Proteksi Tanaman, Fakultas Pertanian, Universitas Lampung, Jl. Prof. Sumantri Brojonegoro No. 1 Bandar Lampung 35145
} 
tirucalli), dan daun nimba (Azadirachta indica) terhadap mortalitas keong emas.

\section{METODE PENELITIAN}

Penelitian ini dilakukan di rumah kaca Fakultas Pertanian, Universitas Lampung. Penelitian berlangsung sejak bulan Januari sampai Desember 2005. Penelitian ini terdiri dari 4 set percobaan masing-masing adalah uji aplikasi ekstrak kasar buah pinang, akar tuba, patah tulang, dan daun nimba terhadap keong emas. Rancangan percobaan pada masing-masing set percobaan adalah rancangan acak lengkap (RAL), dengan 5 ulangan. Sebagai perlakuan adalah aplikasi ekstrak kasar tumbuhan dengan 5 taraf konsentrasi, kecuali pada uji aplikasi ekstrak kasar akar tuba menggunakan 6 taraf konsentrasi. Penentuan konsentrasi tersebut berdasarkan hasil uji pendahuluan.

Setiap unit satuan percobaan menggunakan 10 ekor keong emas. Jumlah keong emas yang dibutuhkan untuk 4 set percobaan sebanyak 1050 ekor keong emas. Keong emas uji diperoleh dari lapangan (persawahan) dan dipilih yang berukuran panjang tubuh antara 1,5-2,0 cm. Pada saat aplikasi, keong emas uji ditaruh dalam ember yang telah berisi lumpur dan 10 liter air. Selama pengujian keong emas diberi pakan daun talas.

Bahan tumbuhan yang akan diuji dihaluskan dengan menggunakan blender hingga menjadi ekstrak kasar, kecuali buah pinang dihaluskan dengan cara ditumbuk. Ekstrak kasar yang dibuat dapat segera diaplikasikan dengan metode aplikasi langsung pada media hidup keong emas yaitu air yang berada dalam ember. Jumlah ekstrak kasar yang diaplikasikan sesuai dengan konsentrasi yang telah ditetapkan, misalnya untuk perlakuan dengan konsentrasi $1 \mathrm{~g} / 1$ maka 10 gr ekstrak kasar diaplikasikan ke dalam ember yang berisi 101 air. Sebagai bahan perata digunakan detergen dengan dosis $1 \mathrm{~g} / 10$ liter air.

\section{Perlakuan percobaan}

Set 1. Pada uji aplikasi ekstrak kasar buah pinang, 5 taraf konsentrasi ekstrak kasar buah pinang yang diujikan adalah P0 (0 g/l air) sebagai kontrol; P1 (0,5 g/l air); P2 (1,0 g/l air); P3 (2,0 g/l air); dan P4 (3,0 g/ 1 air).
Set 2. Pada uji aplikasi ekstrak kasar akar tuba, 6 taraf konsentrasi ekstrak kasar akar tuba yang diujikan adalah A0 (0 g/l air) sebagai kontrol; A1 (0,6 g/l air); A2 (0,8 g/1 air); A3 (1,0 g/l air); (1,2 g/1 air), dan A4 $(1,4 \mathrm{~g} / \mathrm{l}$ air).

Set 3. Pada uji aplikasi ekstrak kasar patah tulang, 5 taraf konsentrasi ekstrak kasar patah tulang yang diujikan adalah T0 (0 g/l air) sebagai kontrol; T1 (2 g/l air); T2 (4 g/l air); T3 (6g/l air); dan T4 (8 g/l air).

Set 4. Pada uji aplikasi ekstrak kasar daun nimba, 5 taraf konsentrasi ekstrak kasar daun nimba yang diujikan adalah N0 (0 g/l air) sebagai kontrol; N1 (1 g/1 air); N2 (2 g/l air); N3 (3 g/l air); dan N4 (4 g/l air).

Pengamatan terhadap mortalitas keong emas dilakukan setiap 12 jam sampai 72 jam setelah aplikasi (jsa). Data mortalitas keong emas dari masing-masing set percobaan diolah dengan analisis ragam dan dilanjutkan dengan uji BNT taraf nyata $5 \%$.

\section{HASIL DAN PEMBAHASAN}

Aplikasi ekstrak kasar buah pinang terhadap keong emas. Aplikasi ekstrak kasar buah pinang menyebabkan keong emas uji menunjukkan gejala keracunan dan kematian. Keong emas yang keracunan menunjukkan gejala seperti tidak aktif makan, operkulum tertutup, tidak respon bila disentuh, dan pada bagian tubuh yang lunak terjadi perubahan warna (menjadi merah kecoklatan). Pada tahap selanjutnya keong emas akan mati.

Mortalitas keong emas telah tercatat sejak pengamatan pertama (12 jsa), dengan tingkat mortalitas yang bervariasi yaitu $24 \%$ pada perlakuan konsentrasi terendah $(0,5 \mathrm{~g} / \mathrm{l})$ dan $56 \%$ pada perlakuan konsentrasi tertinggi (3 g/l) (Tabel 1). Keong emas yang mati menunjukkan gejala seperti tubuhnya menjorok ke luar cangkang, warna tubuh menjadi gelap, dan mengambang di permukaan air.

Pada Tabel 1 terlihat bahwa mortalitas keong emas meningkat cukup tinggi pada pengamatan 24 jsa. Pada pengamatan 60 jsa, perlakuan aplikasi ekstrak kasar buah pinang dengan konsentrasi terendah $(0,5$ $\mathrm{g} / \mathrm{l})$ telah menimbulkan mortalitas keong emas $100 \%$, demikian pula halnya dengan konsentrasi-konsentrasi yang lebih tinggi. 
Tabel 1. Persentase mortalitas keong emas pasca aplikasi ekstrak kasar buah pinang

\begin{tabular}{ccrcccc}
\hline \multirow{2}{*}{$\begin{array}{c}\text { Konsentrasi } \\
(\mathrm{g} / \mathrm{l})\end{array}$} & 12 & 24 & 36 & 48 & 60 & 72 \\
\cline { 2 - 6 } & $0 \mathrm{a}$ & $0 \mathrm{a}$ & $0 \mathrm{a}$ & $0 \mathrm{a}$ & $0 \mathrm{a}$ & $0 \mathrm{a}$ \\
0 & $24 \mathrm{~b}$ & $62 \mathrm{~b}$ & $70 \mathrm{~b}$ & $80 \mathrm{~b}$ & $100 \mathrm{~b}$ & $100 \mathrm{~b}$ \\
0,5 & $28 \mathrm{~b}$ & $90 \mathrm{c}$ & $100 \mathrm{c}$ & $100 \mathrm{c}$ & $100 \mathrm{~b}$ & $100 \mathrm{~b}$ \\
1,0 & $38 \mathrm{c}$ & $96 \mathrm{c}$ & $100 \mathrm{c}$ & $100 \mathrm{c}$ & $100 \mathrm{~b}$ & $100 \mathrm{~b}$ \\
2,0 & $56 \mathrm{~d}$ & $100 \mathrm{c}$ & $100 \mathrm{c}$ & $100 \mathrm{c}$ & $100 \mathrm{~b}$ & $100 \mathrm{~b}$ \\
3,0 &
\end{tabular}

Angka sekolom yang diikuti huruf yang sama tidak berbeda nyata menurut Uji BNT pada taraf nyata 5\%.

Data pengamatan di atas menunjukkan bahwa ekstrak kasar buah pinang mengandung senyawa yang mempunyai toksisitas cukup tinggi terhadap keong emas. Buah pinang mengandung senyawa alkaloid, yaitu norrorecaidine, norroricoline, arecaidine, arecaine, arecolidine, gufacine, gufacoline, dan isoguacine (Wijayakusuma, 1996). Buah pinang telah dikenal berpotensi sebagai bakterisida nabati (Direktorat Bina Perlindungan Tanaman Perkebunan, 1994), ternyata juga berpotensi sebagai moluskisida nabati.

\section{Aplikasi ekstrak kasar akar tuba terhadap keong} emas. Pada pengamatan pertama (12 jsa), aplikasi ekstrak kasar akar tuba telah menyebabkan mortalitas keong emas namun saat itu persentase mortalitas masih rendah. Keong emas yang masih hidup menunjukkan gejala keracunan akibat aplikasi ekstrak kasar akar tuba.

Pada pengamatan 24 sampai 60 jsa, terjadi peningkatan mortalitas keong emas. Pada pengamatan 60 jsa, perlakuan aplikasi ekstrak kasar akar tuba dengan konsentrasi $0,8 \mathrm{~g} / 1$ menyebabkan mortalitas yang cukup tinggi yaitu $90 \%$, sedangkan pada perlakuan dengan konsentrasi yang lebih tinggi mortalitas keong emas telah mencapai 100\% (Tabel 2). Mortalitas keong emas tersebut menunjukkan indikasi bahwa kandungan bahan dalam akar tuba menyebabkan kematian keong emas. Akar tuba selama ini dikenal sebagai bahan untuk meracuni ikan di sungai, ternyata juga bersifat toksik terhadap keong emas. Akar tuba mengandung senyawa aktif rotenoid yang dapat mempengaruhi enzim respirasi serangga OPT seperti Spodoptera litura, Crocidolomia binotalis, dan nematoda Meloidogyne incognita (Direktorat Bina Perlindungan Tanaman Perkebunan,
1994). Sedangkan menurut Georgy dan Teik (1932), bahan aktif yang dimiliki oleh akar tuba selain rotenon juga mengandung deguelin, teprosin, dan toksikarol. Kandungan bahan bahan tersebut banyak dijumpai pada bagian akar tanaman D. elliptica.

Aplikasi ekstrak kasar buah pinang dengan konsentrasi $0,5 \mathrm{~g} / 1$ dan ekstrak kasar akar tuba dengan konsentrasi $1 \mathrm{~g} / 1$ pada pengamatan 60 jsa telah menyebabkan mortalitas sebesar $100 \%$ keong emas uji, hal ini menunjukkan kedua jenis bahan tumbuhan tersebut mempunyai toksisitas cukup tinggi terhadap keong emas.

Aplikasi ekstrak kasar patah tulang terhadap keong emas. Keong emas uji menunjukkan gejala keracunan pasca aplikasi ekstrak kasar patah tulang. Gejala keong emas yang keracunan tersebut antara lain keong emas mengeluarkan lendir, tidak aktif makan, operkulum tertutup, dan tidak respon terhadap rangsangan. Aplikasi ekstrak kasar patah tulang secara nyata berpengaruh terhadap mortalitas keong emas.

Pada pengamatan 12 jsa dan 24 jsa, mortalitas keong emas masih rendah bahkan pada perlakuan aplikasi ekstrak kasar patah tulang dengan konsentrasi terendah ( $2 \mathrm{~g} / \mathrm{l}$ air) belum menyebabkan kematian pada keong emas uji. Pada pengamatan 96 jsa, tingkat mortalitas keong emas bervariasi yaitu sebesar $26 \%$ pada perlakuan dengan konsentrasi terendah (2 $\mathrm{g} / 1$ air) dan $84 \%$ pada perlakuan dengan konsentrasi tertinggi ( $8 \mathrm{~g} / 1$ air). Mortalitas keong emas antar perlakuan menunjukkan perbedaan yang nyata (Tabel $3)$.

Getah dari tanaman patah tulang dikenal beracun karena dapat menyebabkan iritasi pada kulit dan mata manusia. Tanaman ini juga digunakan untuk meracuni ikan. Getah patah tulang 
Tabel 2. Persentase mortalitas keong emas pasca aplikasi ekstrak kasar akar tuba

\begin{tabular}{ccccccc}
\hline \multirow{2}{*}{$\begin{array}{c}\text { Konsentrasi } \\
(\mathrm{g} / \mathrm{l})\end{array}$} & 12 & 24 & 36 & 48 & 60 & 72 \\
\cline { 2 - 6 } & $0 \mathrm{a}$ & $0 \mathrm{a}$ & $0 \mathrm{a}$ & $0 \mathrm{a}$ & $0 \mathrm{a}$ & $0 \mathrm{a}$ \\
0 & $0 \mathrm{a}$ & $34 \mathrm{~b}$ & $36 \mathrm{~b}$ & $40 \mathrm{~b}$ & $70 \mathrm{~b}$ & $70 \mathrm{~b}$ \\
0,6 & $4 \mathrm{a}$ & $72 \mathrm{c}$ & $78 \mathrm{c}$ & $78 \mathrm{c}$ & $90 \mathrm{c}$ & $90 \mathrm{c}$ \\
0,8 & $20 \mathrm{bc}$ & $82 \mathrm{~cd}$ & $90 \mathrm{~d}$ & $94 \mathrm{c}$ & $100 \mathrm{c}$ & $100 \mathrm{c}$ \\
1,0 & $16 \mathrm{~b}$ & $92 \mathrm{~d}$ & $100 \mathrm{~d}$ & $100 \mathrm{c}$ & $100 \mathrm{c}$ & $100 \mathrm{c}$ \\
1,2 & $24 \mathrm{c}$ & $94 \mathrm{~d}$ & $100 \mathrm{~d}$ & $100 \mathrm{c}$ & $100 \mathrm{c}$ & $100 \mathrm{c}$ \\
1,4 &
\end{tabular}

Angka sekolom yang diikuti huruf yang sama tidak berbeda nyata menurut Uji BNT pada taraf nyata 5\%.

Tabel 3. Persentase mortalitas keong emas pasca aplikasi ekstrak kasar patah tulang

\begin{tabular}{cccccccc}
\hline \multirow{2}{*}{$\begin{array}{c}\text { Konsentrasi } \\
(\mathrm{g} / \mathrm{l})\end{array}$} & 12 & 24 & 36 & 48 & 60 & 72 & 96 \\
\cline { 2 - 8 } & $0 \mathrm{a}$ & $0 \mathrm{a}$ & $0 \mathrm{a}$ & $0 \mathrm{a}$ & $0 \mathrm{a}$ & $0 \mathrm{a}$ & $0 \mathrm{a}$ \\
2 & $0 \mathrm{a}$ & $0 \mathrm{a}$ & $6 \mathrm{~b}$ & $8 \mathrm{~b}$ & $12 \mathrm{~b}$ & $16 \mathrm{~b}$ & $26 \mathrm{~b}$ \\
4 & $0 \mathrm{a}$ & $4 \mathrm{a}$ & $10 \mathrm{~b}$ & $16 \mathrm{c}$ & $24 \mathrm{~b}$ & $34 \mathrm{c}$ & $52 \mathrm{c}$ \\
6 & $12 \mathrm{~b}$ & $18 \mathrm{~b}$ & $30 \mathrm{c}$ & $40 \mathrm{~d}$ & $50 \mathrm{c}$ & $58 \mathrm{~d}$ & $64 \mathrm{~d}$ \\
8 & $24 \mathrm{c}$ & $34 \mathrm{c}$ & $40 \mathrm{~d}$ & $54 \mathrm{e}$ & $62 \mathrm{c}$ & $74 \mathrm{e}$ & $84 \mathrm{e}$ \\
\hline
\end{tabular}

Angka sekolom yang diikuti huruf yang sama tidak berbeda nyata menurut Uji BNT pada taraf nyata 5\%.

mengandung senyawa euphobone, taraksasterol, $\alpha$ laktucerol, euphol; merupakan senyawa damar dengan rasa tajam dan pahit (Wijayakusuma, 1996). Pada pengujian ini mortalitas tidak mencapai $100 \%$. Keong emas uji yang tidak mati pasca aplikasi ekstrak kasar patah tulang meskipun menunjukkan gejala keracunan, namun masih dapat melekat pada ember atau daun talas yang disediakan, aktivitas makan sangat menurun, dan gerakan sangat lamban.

\section{Aplikasi ekstrak kasar daun nimba terhadap} keong emas. Hasil pengamatan pada 12 jam setelah efikasi ekstrak kasar daun nimba ternyata belum menimbulkan pengaruh yang mematikan terhadap keong emas uji pada semua taraf konsentrasi. Kematian keong emas uji baru tampak pada pengamatan 24 jsa, itupun masih dalam persentase yang rendah (tidak lebih dari 12\%). Pada pengamatan selanjutnya mortalitas keong emas terus meningkat, meskipun laju peningkatannya sangat rendah.

Tingkat mortalitas $100 \%$ keong emas uji terjadi pada pengamatan 96 jsa pada perlakuan aplikasi ekstrak kasar daun nimba dengan konsentrasi tertinggi
(4 g/l), pada perlakuan dengan konsentrasi yang lebih rendah secara nyata menunjukkan persentase mortalitas yang lebih rendah (Tabel 4). Pada perlakuan aplikasi ekstrak kasar daun nimba dengan konsentrasi $1 \mathrm{~g} / 1$ air, mortalitas keong emas uji hanya mencapai 58\%. Tanaman nimba telah dikenal sebagai pestisida nabati dan dapat mengendalikan hama ulat grayak, kutu daun, ulat kubis, dan wereng. Daun nimba mengandung senyawa azadirachtin, meliantriol, salanin, dan nimbin (Direktorat Bina Perlindungan Tanaman Perkebunan, 1994). Senyawa tersebut dapat mengganggu pertumbuhan dan reproduksi serangga, serta dapat membunuh serangga (Kardinan, 1999).

Dari keempat bahan tumbuhan yang diujikan dalam percobaan ini, terlihat bahwa buah pinang dan akar tuba memiliki daya toksik yang tinggi terhadap keong emas. Pada aplikasi dengan konsentrasi yang cukup rendah ekstrak kasar buah pinang $(0,5 \mathrm{~g} / \mathrm{l})$ dan akar tuba $(1 \mathrm{~g} / \mathrm{l})$ telah menyebabkan mortalitas $100 \%$ keong emas uji dalam waktu yang relatif singkat. Hasil ini juga lebih tinggi jika dibandingkan hasil penelitian Salaki (2001), yang menyebutkan bahwa 
Tabel 4. Persentase mortalitas keong emas pasca aplikasi ekstrak kasar daun nimba

\begin{tabular}{ccccccccc}
\hline \multirow{2}{*}{$\begin{array}{c}\text { Konsentrasi } \\
(\mathrm{g} / \mathrm{l})\end{array}$} & 12 & 24 & 36 & 48 & 60 & 72 & 84 & 96 \\
\hline 0 & $0 \mathrm{a}$ & $0 \mathrm{a}$ & $0 \mathrm{a}$ & $0 \mathrm{a}$ & $0 \mathrm{a}$ & $0 \mathrm{a}$ & $0 \mathrm{a}$ & $0 \mathrm{a}$ \\
1 & $0 \mathrm{a}$ & $6 \mathrm{~b}$ & $20 \mathrm{~b}$ & $22 \mathrm{~b}$ & $32 \mathrm{~b}$ & $40 \mathrm{~b}$ & $49 \mathrm{~b}$ & $58 \mathrm{~b}$ \\
2 & $0 \mathrm{a}$ & $8 \mathrm{~b}$ & $26 \mathrm{bc}$ & $32 \mathrm{c}$ & $44 \mathrm{c}$ & $50 \mathrm{c}$ & $61 \mathrm{c}$ & $73 \mathrm{c}$ \\
3 & $0 \mathrm{a}$ & $8 \mathrm{~b}$ & $30 \mathrm{~cd}$ & $32 \mathrm{c}$ & $46 \mathrm{c}$ & $52 \mathrm{c}$ & $66 \mathrm{c}$ & $83 \mathrm{~d}$ \\
4 & $0 \mathrm{a}$ & $12 \mathrm{c}$ & $34 \mathrm{~d}$ & $42 \mathrm{~d}$ & $60 \mathrm{~d}$ & $70 \mathrm{~d}$ & $85 \mathrm{~d}$ & $100 \mathrm{e}$ \\
\hline
\end{tabular}

Angka sekolom yang diikuti huruf yang sama tidak berbeda nyata menurut Uji BNT pada taraf nyata 5\%.

mortalitas keong emas tertinggi sebesar $82,7 \%$ akibat aplikasi ekstrak biji pala dengan konsentrasi $40 \%$. Sedangkan aplikasi ekstrak kasar patah tulang $(8 \mathrm{~g} / \mathrm{l})$ dapat menyebabkan mortalitas keong emas sebesar $84 \%$ dan aplikasi ekstrak kasar daun nimba (4 g/l) menyebabkan mortalitas keong emas sebesar $100 \%$ pada 96 jsa.

Pengendalian keong emas yang dilakukan oleh petani saat ini umumnya dilakukan secara mekanik, yaitu dengan mengambil keong emas dengan tangan lalu dibunuh. Untuk mempermudah pengambilan keong emas, petani biasanya membuat parit di bagian tepi petak sawah. Keong emas akan terkumpul (terkonsentrasi) pada parit tersebut karena keong emas menyukai tempat yang lebih tergenang.

Cara yang biasa dilakukan oleh petani ini dapat juga digunakan untuk meningkatkan efisiensi pengendalian dengan ekstrak kasar moluskisida nabati. Ekstrak kasar moluskisida nabati tersebut langsung saja diaplikasikan ke parit dalam petak sawah. Keong emas yang terkonsentrasi di parit akan terbunuh karena aplikasi moluskisida nabati tersebut.

Aplikasi ekstrak kasar moluskisida nabati dapat dijadikan salah satu alternatif pengendalian dalam pengendalian hama terpadu (PHT) terhadap keong emas. Aplikasi ekstrak kasar moluskisida nabati cukup ekonomis karena bahan moluskisida nabati ini cukup murah dan mudah diperoleh serta cukup aman dan ramah lingkungan karena bahan yang digunakan bersifat mudah terurai.

\section{SIMPULAN DAN SARAN}

Buah pinang dan akar tuba mempunyai daya racun yang cukup kuat terhadap keong emas. Aplikasi dengan konsentrasi terendah ekstrak kasar buah pinang $(0,5 \mathrm{~g} / \mathrm{l})$ dan akar tuba $(1 \mathrm{~g} / \mathrm{l})$ telah menyebabkan mortalitas $100 \%$ keong emas uji. Sedangkan aplikasi ekstrak kasar patah tulang $(8 \mathrm{~g} / \mathrm{l})$ menyebabkan mortalitas keong emas sebesar $84 \%$ dan aplikasi ekstrak kasar daun nimba (4 g/l) menyebabkan mortalitas keong emas sebesar 100\% pada 96 jsa.

Perlu dilakukan penelitian lebih lanjut untuk mengetahui LC50 dari bahan moluskisida nabati tersebut. Penelitian skala lapangan juga sangat diperlukan untuk melihat efektifitas berbagai bahan moluskisida nabati tersebut dalam pengendalian keong emas pada pertanaman padi di sawah.

\section{SANWACANA}

Ucapan terima kasih kami sampaikan kepada Pumei Ardianto, Ridwan Achmadi, Andre Martin, dan Rahmat Nurcahyo yang telah membantu pelaksanaan penelitian ini.

\section{DAFTAR PUSTAKA}

Alis, F. 1997. Pertumbuhan Keong Murbei (Pomacea sp.) yang Diberi Pakan Beberapa Jenis Tumbuhan. Skripsi. Fakultas Pertanian, Institut Pertanian Bogor. $28 \mathrm{hlm}$.

Direktorat Bina Perlindungan Tanaman Perkebunan. 1994. Pedoman Pengenalan Pestisida Botani. Direktorat Jenderal Tanaman Perkebunan, Departeman Pertanian. Jakarta. $85 \mathrm{hlm}$.

Djajasasmita, M. 1999. Keong dan Kerang Sawah. Seri Panduan Lapangan.

Puslitbang Biologi LIPI. Bogor. Fajar. 2005. Petani Trauma Hama Keong Emas. 
$<$ http://fajar.co.id/news.php. Diakses September 2005>

Georgy, C.D.V. and G.L. Teik. 1932. The Rotenon Content of Malayan Tuba Root. The Malayan Agricultural Journal. XVIII : 326-363.

Grainge, M. and S. Achmed. 1998. Handbook of Plants with Pest Control Properties. John Wiley \& Sons. New York.

Indomedia. 2005. Keong Emas Serang Lahan Pertanian.<http:/www.indomedia.com/bpost/08 2004/11/kalsel/lbm9.htm Diakses 7 September 2005>

Kardinan, A. 1999. Pestisida Nabati, Ramuan dan Aplikasi. Penebar Swadaya. Jakarta

Kompas. 2005. Petani Keluhkan Serangan hama Keong Emas.

$<$ http://www.kompas.co.id/kompas-cetak.

Diakses 7 September 2005>
7 Oka, I.N. 1994. Penggunaan, Permasalahan serta Prospek Pestisida Nabati dalam Pengendalian Hama Terpadu. Prosiding Seminar Hasil Penelitian dalam Rangka Pemanfaatan Pestisida Nabati. Bogor, 1-2 Desember 1993. Balai Penelitian Tanaman Rempah dan Obat, Badan Penelitian dan Pengembangan Pertanian. Departemen Pertanian. Hlm. 1-10.

Pikiran-rakyat. 2005. Keong Emas Rusak $40 \mathrm{Ha}$ Padi. <http://www. pikiran-rakyat.com/cetak. Diakses 7 September 2005>

Pitojo, S. 1996. Petunjuk Pengendalian dan Pemanfaatan Keong Emas. Trubus Agrowijaya, Ungaran. $106 \mathrm{hlm}$.

Salaki, C.L. 2001. Penggunaan Ekstrak Biji Pala untuk Mengendalikan Populasi Siput Emas (Pomacea caniculata). J. Eugenia Vol. 7 (3): 23-25.

Wijayakusuma, H. 1996. Tanaman Berhasiat Obat di Indonesia. Jilid IV. Pustaka Kartini. Jakarta 